\title{
Do students and canteen vendors think differently about food segregation?
}

\author{
Ratna Djuwita ${ }^{1,}$, Ashma Affifah ${ }^{1}$, and Christina Wulandari ${ }^{1}$ \\ ${ }^{1}$ Faculty of Psychology, Universitas Indonesia, Depok, 16424, Indonesia
}

\begin{abstract}
In university "X" (UX), littering is no longer a problem, but segregating waste is still not evident. Logically, students and canteen vendors are the ones who produce most of the waste. In this study, the authors want to explore whether students would think differently about handling waste compared to canteen vendors. Using the theory of planned behavior as the theoretical framework, the authors indeed found that students compared with canteen vendors had significantly different attitudes, norms, and perceived behavior control. Students have a more positive attitude towards waste segregation, but they do not perceive it as an essential norm that the canteen vendors perceive. Interestingly, canteen vendors segregate food waste, but students do not segregate. After checking it qualitatively, canteen vendors segregate their waste because they are obliged to the faculty management rules. And the reason for students' lower performance in segregating waste is that they do not know the campus' program of waste management. It is concluded that the lack of socialization hinders student's pro-environmental behavior, and the waste segregating behavior from canteen vendors is affected by the existing norms and rules.
\end{abstract}

\section{Introduction}

Modernity and industrialization have made human life more comfortable and increased quality of life. Human life has become more comfortable and more practical because of the products produced by the industry. For example, plastic and styrofoam as food packaging have helped the development of the retail food industry. However, apart from the positive things, adverse side effects such as the accumulation of garbage and the amount of waste that cannot be managed effectively are still an important problem. The government, NGOs, and various educational institutions have made various efforts to reduce, reuse, and recycle the waste they produce. One of the appeals that is now being endorsed is to sort and segregate waste from the source. This means that segregation should begin at the individual level. We can see the government already provided trash bins on streets and public areas, which are already labeled to make it easy for individuals to segregate their waste. The appeal to segregate waste has also been applied by universities, for example, in the university "X" (will be mentioned as "UX").

\footnotetext{
*Corresponding author: juwita@ui.ac.id
} 
As one of the renowned universities in West Java, Indonesia, UX has supported the idea of reducing waste by segregating it since 2018. At a glance, the UX campus is a beautiful and clean environment from rubbish. UX is also one of the campuses with a good GreenMetrix rank, where the success of sustainable waste management is one of the requirements for the ranking. In the UX campus, waste originating from the faculties and the campus ground (like leaves) is sorted and processed. The UX facility management already provided trash bins differentiated into three categories: wet or organic waste, recyclable waste, and residue waste (other than those two categories). The wet or organic waste will be made as compost or fish pellets, while those that cannot be recycled will be sold to a waste bank, and only the rest will be brought to landfills (Y, personal communication, March 2018). This effort will only run effectively and efficiently if supported by UX campus users like students, lecturers, administration staff, guests, and the vendors who work in the campus area. But even though at a glance, the UX campus looks clean from garbage and waste, based on the observation done by the authors (before this study was done), the segregated trash bins in UX was filled with unsegregated waste (see Figure 1).

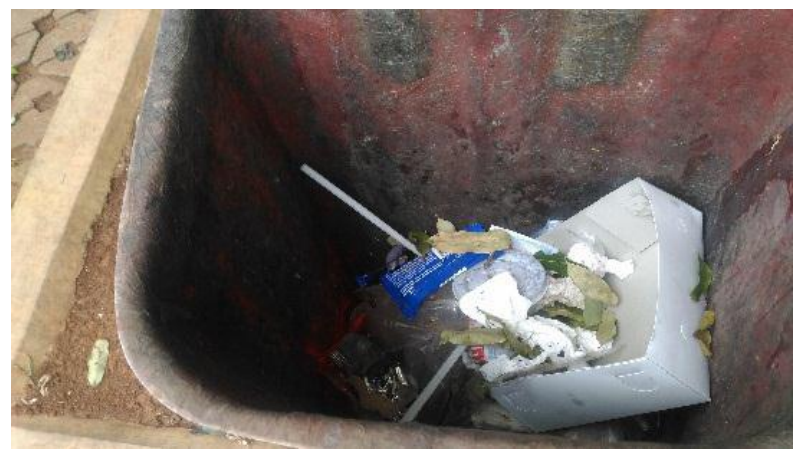

Fig 1. Unsegregated waste in one of the trash bins of UX. Privat documentary

A picture can tell more than words, and this picture tells the fact that the campus users, whose majority are the students, do not segregate their waste. Most of the waste that students produce is food waste, which they bring or they buy from canteen vendors. As a result, the cleaning staff has to sort the waste from the trash, which causes the waste processing process to be inefficient. As an academic institution, it can be assumed that the stakeholders are well informed about the importance of waste segregation. From this perspective, the authors see a problem that should be explored: What factors hinder students from segregating their waste? And because canteen food vendors are also another user that produces food waste, the purpose of this study is to compare the UX student's and food vendors' way of thinking related to food waste segregating. To understand how these two different stakeholder thinks, we use the theory of Planned Behavior [1]. By understanding their attitudes, norms, perceptions of the ability, and intention towards food waste segregation, this knowledge can help UX to plan an intervention so that the waste segregation process in UX can run more efficiently and effectively.

Theory of Planned Behavior (TPB) describes the kind of behavior over which people can apply their self-control. This theory explains that the nearest variable to measure real behavior is to do a particular specific behavior. Based on the Theory of Planned Behavior or TPB [2], three things underlie human behavior. The first thing is the belief in the impact of behavior and evaluation on it, known as behavioral belief or attitude. The second is the belief in other people's expectations or the norm, which is considered valid and is called the subjective norm. The third is the individual's belief that he can control and is called as perceived behavior control (PBC). These three beliefs influence each other in forming the 
actual individual behavior. Attitudes, subjective norms, and $\mathrm{PBC}$ together influence behavioral intentions. The stronger the correlation between each variable and the intention, the higher the variable can predict behavioral intentions, which results in increased intention. The TPB postulate is that the higher a person's intention to perform a particular behavior, the higher is the tendency to do the actual behavior. But this theory also explains that if an individual has substantial control to perform a behavior, this person can immediately carry out the behavior (see Figure 2).

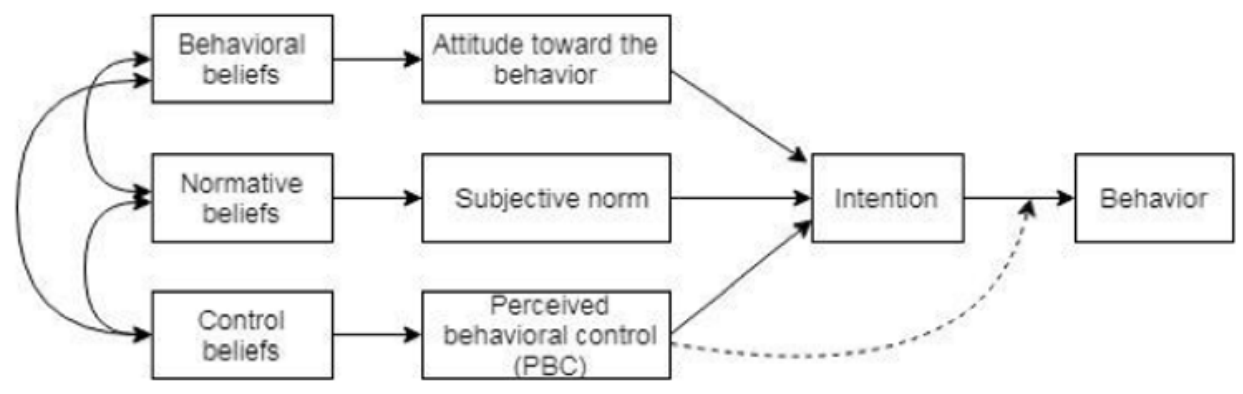

Fig 2. TPB Framework. Source: Thesis, Wulandari, 2019

Regarding waste segregation behavior, several studies use this TPB theoretical framework to understand the dynamic between factors that influence individual intention and waste segregation behavior. Several studies showed that attitudes, subjective norms, and PBC were found as a variable that can predict a person's intention to sort waste [3]. Based on the TPB theory, the higher the individual's positive attitude regarding sorting waste, the higher the individual perceives other people are expecting him to sort waste. The higher the individual perceives himself to segregate, the higher the intention to sort waste. If the intention to segregate waste increases, the likelihood of segregating waste behavior will also increase.

\section{Method}

This research is conducted using two steps. At the first stage, the authors conducted qualitative research to gain knowledge from students and canteen food vendors' perspectives on waste segregation in the UX campus. In the second stage, a quantitative study was conducted by distributing questionnaires to both group samples.

\subsection{Study 1: Qualitative study}

This qualitative study was conducted with semi-structured interview guidelines and observation format towards UX students and canteen vendors. Using the interview and observation method is to better understand of how students and canteen food vendors perceive food waste segregation [4]. The observation was done to have an objective picture of the real situation, and interviews were done to understand participants way of thinking related to waste segregation.

The authors interviewed 18 participants: 8 UX students, 3 canteen vendors from several canteens in campus UX, 2 staff from the UX waste management unit, and 5 UX cleaning service staff from several UX faculties. There were 11 women and 7 men who were interviewed. 
Table 1. Question for Semi-Structured Interview.

\begin{tabular}{|c|c|c|}
\hline No & Dimension & Item \\
\hline 1 & Attitudes & Benefits of waste segregation \\
\hline 2. & Normative Referents & $\begin{array}{l}\text { Opinions related to waste segregation in UX } \\
\text { Significant persons who support and who are against waste } \\
\text { segregation in the UX campus? } \\
\text { How do they motivate you? }\end{array}$ \\
\hline 3. & Control & Factors that facilitate and hinder waste segregation behavior \\
\hline 4. & $\begin{array}{l}\text { Facility and waste } \\
\text { management }\end{array}$ & Knowledge about waste management facilities in UX \\
\hline
\end{tabular}

In the interview, the authors investigated students and food vendors attitudes (whether they accept waste segregation as something positive or negative), subjective norm (their perception of what is expected from them when having some waste on UX campus. Other than that, the authors also investigated perceived behavior control (whether they perceive segregating food waste as something they can do themselves or they have the control to do it). The last one is how strong they intend to segregate their food waste on campus UX. From the interviews, the authors intended to understand their opinion and reason, whether they do or do not segregate their behavior (see table 1).

After or before doing the interview, the authors also observed what was happening in canteens, how students and canteen vendors behave regarding food waste faculties. The authors chose to observe the canteens of the faculty or the dormitory because the authors could directly see students and canteen vendors' behavior regarding food waste segregation and how the process of segregating waste took place (see table 2).

Observation data was recorded using an observation sheet, and recorded interview data was transformed into verbatims. The data was coded and labeled with categories. Similar categories were then grouped into broad themes of the TPB's theoretical framework.

Table 2. Observation guide.

\begin{tabular}{lll}
\hline & Waste Segregation Behavior & Waste management in UX \\
\hline Factor & $\begin{array}{l}\text { The accuracy of the behavior of } \\
\text { sorting or not sorting waste by } \\
\text { students (observation of the contents } \\
\text { of trash bins in campus UX) }\end{array}$ & $\begin{array}{l}\text { Schedule and mechanisms for } \\
\text { transporting waste and processing waste } \\
\text { at UX }\end{array}$ \\
\hline
\end{tabular}

Table 3: The conclusion of the qualitative study.

\begin{tabular}{|l|l|l|}
\hline No & Theme & Results \\
\hline 1 & Attitude & $\begin{array}{l}\text { All participants have positive evaluation related to waste segregation } \\
\text { behavior }\end{array}$ \\
\hline 2 & Subjective norm & $\begin{array}{l}\text { There was a need for injunctive norms (such as rules and } \\
\text { consequences) and descriptive norms (such as behavior examples from } \\
\text { others to implement waste segregation behavior (especially for canteen } \\
\text { vendors). }\end{array}$ \\
\hline 3 & $\begin{array}{l}\text { Perceived } \\
\text { Behavioral Control }\end{array}$ & $\begin{array}{l}\text { Driver factors: } \\
\text { The availability of waste bin. } \\
\text { Better and informative signage }\end{array}$ \\
\hline
\end{tabular}




\begin{tabular}{|c|c|c|}
\hline & & $\begin{array}{l}\text { Barrier factors: } \\
\text { - Not enough trash bins } \\
\text { - } \quad \text { Time (need more time) } \\
\text { Unclear and confusing signage on the waste bin }\end{array}$ \\
\hline 4 & $\begin{array}{l}\text { Waste segregation } \\
\text { behavior }\end{array}$ & $\begin{array}{l}\text { Students: } \\
\text { - Do not have any knowledge about waste management on the UX } \\
\text { campus } \\
\text { - Do not segregate because they think all waste will be compiled } \\
\text { together. } \\
\text { Canteen vendors: } \\
\text { - Already had training in waste segregation. } \\
\text { - They used to do it, but some were currently discontinued. } \\
\text { - Canteen vendors in faculties have to segregate to avoid negative } \\
\text { consequences. }\end{array}$ \\
\hline
\end{tabular}

From the interview with students and food vendors, it was known that both groups have a positive attitude towards waste segregating in general. Both groups know that waste segregating is an excellent way to reduce waste produced on the UX campus. Interestingly, students do not have complete information about waste management in UX university. Most of them do not know that the university has a particular unit to recycle organic waste. Students reported that they put their waste in trash bins because they appreciate cleanliness in the university. Still, they do not segregate their waste because they do not see the importance of doing it. Most of the student participants still think that the waste will be compiled together and sent to the landfill. On the contrary, canteen vendors had, in fact, already joined training on how to segregate their waste. The training was an obligation, and the faculties canteen vendors have to segregate their waste every day because they are forced to do it by the management faculty. So, for the canteen vendors, the norm is obligatory, because if they do not correctly segregate their waste from the canteen, it will not be picked up. The ones who still segregate our canteen vendors from the faculties because their waste will not be picked up. Students do not feel obliged to segregate because they still think that the waste will be compiled together. Some of the students also report that they are confused with the signage on the trash bins, and they find the UX campus needs more trash bins. For canteen vendors, the hindering factors are time because they need more time to segregate.

In brief, conclusions from the interview results can be seen in the table below.

\subsection{Study 2: Quantitative Study}

This quantitative part of the research was a cross-sectional study and non-experimental. Using this method is to have some more generalizable data to the population [4]. It was conducted by distributing a questionnaire (a self-report questionnaire) using the TPB framework [5], which measures attitudes, subjective norms, perceived behavioral control, intention, and behavior of sorting waste adapted in language.

Research participants were UX students and food vendors from canteens located in the UX campus. After cleaning the data, the participants were 200 people, which consisted of 110 students (55\%) and 90 canteen vendors (45\%). Based on gender, there were 108 male participants $(54 \%)$ and 92 female participants (46\%). The participants' age was between 18-72 years, with an average age $(\mathrm{M})=25.19$ years.

The sample selection used the convenience sample technique [4]. The questionnaire was distributed to those who happened to be when the authors were collecting data on the UX campus for students. They were asked to fill out the questionnaire on the spot. Due to time constraints, the questionnaire was left behind and taken the next day for canteen vendors. For some elderly canteen 
vendors, the authors had to read aloud the questions, and they gave the answers verbally. The data collection took place around 08.00-11.00 AM.

For all participants, the authors first asked for their willingness to participate. Before filling in the questionnaire, the study's purpose and the time needed to fill in the questionnaire were explained. If the participants agree, the researcher will provide an informed consent sheet to be signed, and after that, the questionnaire will be given to be filled.

The TPB questionnaire used a Likert-type scale with a 6-point scale, where point 1 indicates strongly disagree and point 6 indicates strongly agree. From the analysis of validity (internal consistency) and reliability (Cronbach alpha), it was found that the instrument has good validity (ranging from $0.4-0.7)$ and reliability $(0.7-0.8)$. Also, the researcher added questions about their daily segregation behavior.

Questionnaire data were converted into scores, and data from items that asked for the same construct were averaged. First, it was compared whether there was a mean difference between the research variables in the TPB between students and canteen food vendors. This was done to determine what factors using the TPB framework were different between the two groups of participants. Second, the authors conducted multiple regressions of attitudes, subjective norms, and the intention to segregate. The authors then conducted multiple regressions of the intention and $\mathrm{PBC}$ of the waste segregate behavior in each group. This is done to determine what factors in the TPB influence the intention and waste segregation behavior in each group.

\section{Results and discussion}

\subsection{Comparison of attitudes, subjective norm and PBC scores of students and Canteen Food Vendors}

Table 4. Comparison of TPB variables from students and canteen vendors

\begin{tabular}{llllllll}
\hline & $\begin{array}{l}\text { Students } \\
(\mathrm{n}-110)\end{array}$ & \multicolumn{3}{c}{$\begin{array}{l}\text { Canteen } \\
\text { vendors } \\
(\mathrm{n}-110)\end{array}$} & $\mathrm{t}$ & $\mathrm{p}$ & Cohen's \\
& $\mathrm{M}$ & $\mathrm{SD}$ & $\mathrm{M}$ & $\mathrm{SD}$ & & & \\
\hline & 5.15 & 0.56 & 4.86 & 0.78 & -2.92 & $0,004 * *$ & -0.43 \\
\hline 1.Attitude & 4.21 & 0.84 & 4.59 & 0.91 & 3.03 & $0,003 * *$ & 0.44 \\
2 Subjective Norm & 4.73 & 0.72 & 4.94 & 0.56 & 2.25 & $0,030^{* *}$ & 0.32 \\
3. PBC & 4.52 & 0.76 & 4.47 & 1.06 & -0.38 & 0,72 & -0.06 \\
4. Intention & 4.38 & 0.86 & 4.71 & 0.82 & 0.45 & $0,007 * *$ & 0.39 \\
5. Segregation Behav. & & & & & & 0.45 \\
\hline
\end{tabular}

*significant 1.o.s 95\%; **significant 1.o.s $99 \%$

From table 4, it can be said that there are significant differences between students and food vendors concerning their attitude, subjective norms, perceived behavioral control (PBC), and segregation behavior. Students attitude have a significantly more positive attitude $(\mathrm{M}=5.15, \quad \mathrm{SD}=0.56)$ than canteen food vendors concerning the importance of waste segregation $(\mathrm{M}=4.86, \mathrm{SD}=0.78)$. This means that students do think more positively about waste food segregation. For subjective norms, the canteen vendors have a significantly higher average subjective norm $(\mathrm{M}=4.59, \mathrm{SD}=0.91)$ than the students. For waste segregation, food vendors are more determined by the expectation of others than students. The food vendors $\operatorname{PBC}(\mathrm{M}=4.94, \mathrm{SD}=0.56)$ is also significantly than the students $(\mathrm{M}=4.73, \mathrm{SD}=0.72)$.

This means that the food vendors on the UX campus are perceived themselves more able to control if they want to segregate than the students. Students and food vendors are not significantly different in their intentions to segregate in the future. Both mean scores are slightly over the median but not very high. For the segregation behavior, canteen food vendors $(\mathrm{M}=4.71, \mathrm{SD}=0.82)$ have a significantly higher average score than students $(\mathrm{M}=$ 
$4.38, \mathrm{SD}=0,86)$. The result explained above already explained that students differ in their way of thinking concerning food waste segregation.

\subsection{Students waste segregating behaviour with the TPB framework}

From the results of the multiple regressions, it is known that there is a significant mutual influence from attitudes, subjective norms and perceived behavioral control on the intention to dispose of waste $\left(\mathrm{F}(3,106)=13.49, \mathrm{p}=0.000, \mathrm{R}^{2}=0.27\right)$. The predictors that significantly influenced the intention of sorting waste were subjective norms $(\mathrm{t}=2.57, \mathrm{p}=0.01)$ and $\mathrm{PBC}$ $(\mathrm{t}=3.88, \mathrm{p}=0.00)$ but it turned out that attitude $(\mathrm{t}=0.74, \mathrm{p}=0.46)$ does not significantly affect the intention in sorting waste.

Table 5 shows the contribution of subjective norms, and $\mathrm{PBC}$ is significant and positive for waste segregation behavior. This means that the higher the subjective norms and $\mathrm{PBC}$ for sorting waste, the higher the intention for students to segregate waste and vice versa. The most considerable contribution to intention comes from PBC.

Tabel 5..Regression analysis of students waste segregation behaviour.

\begin{tabular}{llll}
\hline & B & SE B & Beta \\
\hline Constant & 1,37 & 0,65 & \\
Attitude & 0,09 & 0,12 & 0,07 \\
Subjective Norm & 0,22 & 0,09 & $0.24^{*}$ \\
$P B C$ & 0,37 & 0,10 & $0,25^{* *}$ \\
\hline
\end{tabular}

*significant 1.o.s 95\%; **significant l.o.s 99\%

Multiple regression analysis also found a mutual contribution from intention and $\mathrm{PBC}$ to waste sorting behavior $\left(\mathrm{F}(2.107)=37.68, \mathrm{p}=0.000, \mathrm{R}^{2}=0.41\right)$. The predictors that significantly influenced the waste sorting behavior were PBC $(\mathrm{t}=7.06, \mathrm{p}=0.000)$ and the intention $(\mathrm{t}=1.19, \mathrm{p}=0.24)$ did not predict the waste sorting behavior. PBC explains $41 \%$ of the variance of waste sorting behavior. Intention does not significantly affect sorting behavior, so it negates the role of subjective attitudes and norms in waste sorting behavior.

\subsection{Canteen vendors waste segregating behaviour with the TPB framework}

From the results of the multiple regression, it is known that the model is significant for the intention to segregate food waste $(\mathrm{F}(3.86)=6.08, \mathrm{p}=0.001, \mathrm{R} 2=0.18)$. It was also found that only attitudes $(t=-0.24, p=0.02)$ and subjective norms $(t=3.20, p=0.002)$ significantly influenced the intention to segregate waste, but it turned out that perceived behavioral control $(t=1.02), p=0.31)$ did not significantly affect the intention to sort the waste.

The results in Table 6 shows that attitudes have a negative contribution to the intention of waste segregation. This means that the lower the individual's attitude towards sorting the waste, the higher is the canteen vendors intention to throw away the waste and vice versa. The most significant contribution to intention comes from subjective norms.

Table 6. Regression analysis of canteen vendors waste segregation behavior.

\begin{tabular}{llll}
\hline & B & SE B & Beta \\
\hline Constant & 3,12 & 1,03 & \\
Attitude & $-0,32$ & 0,14 & $-0,24^{*}$ \\
Subjective Norm & 0,41 & 0,13 & $0,35^{*}$ \\
$P B C$ & 0,21 & 0,21 & 0,11 \\
\hline
\end{tabular}

*significant 1.o.s 95\%; ${ }^{* *}$ significant 1.o.s $99 \%$ 
From the results of multiple regressions, it is known that the model of behavior using the TPB construct is significant for the waste sorting behavior variable $(\mathrm{F}(2.87)=11.12, \mathrm{p}=$ $0.000, \mathrm{R} 2=0.20)$. In contrast to the theory of planned behavior framework, the multiple regression on waste sorting behavior shows that only perceived behavioral control $(t=4.50$, $\mathrm{p}=0.00$ ) affects waste sorting behavior among UX Canteen vendors. Simultaneously, the intention has no significant contribution to waste segregating behavior $(t=0.43, p=0.67)$.

From table 6, it can be concluded that only PBC affects the waste sorting behavior and explains $20 \%$ of the variance in the waste sorting behavior. Intention does not significantly affect sorting behavior, so it negates the role of subjective attitudes and norms in sorting waste behavior. The hypothesis that the researchers proposed was not proven because (1) only subjective attitudes and norms contributed significantly to the intention, and (2) only perceived behavioral control significantly contributed to waste sorting behavior.

\subsection{The conclusion of a quantitative study}

Comparing UX students and canteen vendors related to waste segregation with the TPB framework, we found that significantly students have a more positive attitude than the canteen vendors. Still, their subjective norms and PBC are lower than canteen vendors. The most exciting result is that canteen vendors have a significantly higher result in segregation behavior, even though their attitude towards waste segregation is lower than the students. From the multiple analyses, we know that students' significant contributions are the subjective norm and $\mathrm{PBC}$, while the canteen vendors are the subjective norm.

This means that canteen vendors do not have a positive evaluation of waste segregation, but they still do it because of the norms. While students know that food segregation is essential, they also acknowledge it as an acceptable norm and know that they can segregate, but they do not perform it.

\subsection{Discussion}

The author's interest was comparing students and canteen food vendors in university UX concerning waste segregation. Answering the research question, "Do students and canteen vendors think differently about food segregation?" the data collected shows that UX students do think differently than the canteen vendors. From the quantitative study, we know that students have a more positive attitude towards waste segregation. Still, when compared, the food vendors' waste segregation behavior was significantly higher than the students. This difference can be explained by the qualitative data obtained from the interviews, besides the subjective norm and PBC data.

From the interview, which is consistent with the quantitative results, students do have a positive attitude; they think that segregating food waste in the UX campus is an excellent social norm and thinks that they can do it. The reason they do not segregate their waste in the UX campus comes from a lack of information. From the interview, we know that students still think that the waste collected in the UX campus will be collected together without being segregated and processed. They do not know about waste management in the UX campus. UX university already has a waste management unit that recycles organic waste and works with a waste bank. Some are also still confused with the signage.

On the contrary, the canteen vendors do not appreciate waste segregation, they even have a negative attitude, but their behavior in segregating food waste is significantly higher. They are segregating waste because they have a pro-environmental belief, but because they do not have any choice. The only factor that significantly contributes to their intention to segregate their waste is that they perceive that their social environment requires them to do so (norms). Their behavior is influenced by PBC. As vendors, they must oblige to the UX management 
rules (represented by the subjective norms). When they do not segregate their waste, the waste facility unit will not pick up their waste, and they will get negative sanctions from the faculty management. And because the waste management system has been running since 2018, the food vendors are already accustomed to doing it. This explained why the food vendors also have a higher PBC than the students.

For both groups, the subjective norm seems to be an essential part which can influence the intention. This is also consistent with qualitative findings that the existence of rules and examples from others influences individuals to do the waste segregation. The findings of the contribution of subjective norms are by the previous research, who emphasize the importance of the role of subjective norms [6]. These findings may reflect a way to implement new proenvironmental behavior in Indonesian society [7]. The significant population of Indonesia and the big educational gap require a more deterministic approach.

This research showed that a mixed-method approach using qualitative and quantitative data is essential. The qualitative and quantitative study related to the segregation behavior of students and canteen vendors complemented each other- The qualitative data from the interview and observation provided objective data and gave a deep understanding of the quantitative responses. Students are not segregating their waste because they do not have a pro-environmental belief, but because they lack information. And the food vendors segregate their food waste because of UX management regulations, not because they believe in being pro-environmental. Humans choose to do meaningful behavior; if they are not forced to do something is essential to develop interventions promoting environmental behavior.

\section{Conclusion}

Students and Canteen Food Vendors thinks differently about doing food waste segregation in the UX Campus. Students do think that food segregation is a good thing to do, but they did not have the knowledge that UX Campus has already provide the facilities to recycle the waste coming from the faculties and canteens. Because students still think all waste will be mixed and brought to the landfill, they are reluctant to do it. On the other hand, the food vendors are segregating their waste, not because of pro-environmental reasons, but because they have to obliged to the rules of the faculty and campus management.

\section{References}

1. I. Ajzen, The theory of planned behavior, Organizational Behavior and Human Decision Processes 50, 2 179-211 (1991) https://doi.org/10.1016/0749-5978(91)90020-T

2. I. Ajzen, The theory of planned behavior is alive and well, and not ready to retire: a commentary on Sniehotta, Presseau, and Araujo-Soares, Health Psychology Review 9, 2 131-137 (2014) https://doi.org/10.1080/17437199.2014.883474

3. T. Gadiraju. (2016). Investigating the determinants of recycling behavior in youth by using theory of planned behavior. University of South Florida

4. R. Kumar, R. (2019). Research methodology A step-by-step guide for beginners. Sage Publications Limited

5. S. Zhang. M. Zhang. X. , H. Ren, (2016). R. C. R. 109 (2016): 176-186.

6. J. Miliute-Plepiene, O. Hage, A. Plepys, A. Reipas, What motivates households recycling behaviour in recycling schemes of different maturity? Lessons from Lithuania and Sweden, Resource, Conservation, and Recycling, 113, 40-52 (2016) https://doi.org/10.1016/j.resconrec.2016.05.008

7. Niaura, A. (2013). Using the Theory of Planned Behavior to Investigate the Determinants of Environmental Behavior among Youth. Environmental Research, Engineering and Management, 63(1), 74-81. https://doi.org/10.5755/j01.erem.63.1.2901 